\title{
La ficcionalización de la lectura: didáctica y política en El beso de la mujer araña
}

\author{
The fictionalization of reading: didactics and politics in Kiss of the Spider \\ Woman
}

\author{
Leonardo Berneri \\ bernerileonardo@gmail.com \\ Universidad Nacional de Rosario, Argentina
}

Cita sugerida: Berneri, L. (2020). La

ficcionalización de la lectura: didáctica y política en

El beso de la mujer araña. Orbis Tertius, 25(30),

e175. https://doi.org/10.24215/18517811e175

\begin{abstract}
Resumen: El beso de la mujer araña, la novela que, para gran parte de la crítica, abre la etapa específicamente política de la obra de Puig, se estructura a partir de la tensión entre dos modos de lectura opuestos: en uno la lectura es una ocasión para la interpretación que se despliega como exégesis hermenéutica, en el otro la lectura aparece como una experiencia que en su acontecer confunde arte y vida en un proceso de afectación mutua. Estos dos modos de lectura son encarnados respectivamente por Valentín y Molina, los dos personajes en conversación en la novela, que entablan un proceso de enseñanza-aprendizaje a través del cual Valentín acabará desentendiéndose de los saberes desde los cuales lee para adoptar el modo de lectura vital de Molina.
\end{abstract}

Palabras clave: Manuel Puig, Ficcionalización de la lectura, Arte y vida.

\begin{abstract}
Kiss of the spider woman, the novel that, according to most critics, opens the specifically political stage of Puig's work, is structured through the tension between two opposite modes of reading: in one of them reading it is an occasion for interpretation that unfolds as hermeneutic exegesis, in the other one reading appears as an experience that confuses art and life in a process of mutual affectation. These two modes of reading are embodied respectively by Valentín and Molina, the two characters in conversation in the novel, who engage in a teaching-learning process through which Valentín will end up ignoring the knowledge from which he reads to adopt Molina's vital way of reading.
\end{abstract}

Keywords: Manuel Puig, Fictionalization of reading, Art and life.

No es difícil imaginar el desconcierto que la publicación de El beso de la mujer araña habrá provocado en sus primeros lectores. ¿Una novela política? ¿Una novela sobre el encierro y la tortura? ¿No era Puig el escritor de las minucias y traiciones de la vida pueblerina? ¿No había sido solo un desliz la incursión en la actualidad citadina de The Buenos Aires Affair, novela que, después de todo, seguía hablando de amores cruzados, envidias, celos y frustraciones? ¿Lo había ganado acaso el clima de época? ¿También Puig hablaría ahora de revolución? ${ }^{1}$ Pronto el lector se habrá sosegado, al menos en parte: Puig había sabido seguir siendo 
Puig. Allí estaba el cine, la ausencia de narrador, las voces coloquiales puestas en conversación, el inestable juego con los lugares comunes a los que sus novelas lo tenían acostumbrado. Aun así, la novela no dejaría de molestar porque, sí, se trataba de un texto abiertamente político que hablaba de la revolución y abría, de esta manera, una nueva etapa en la novelística puiguiana.

El beso de la mujer araña es, en principio, una novela de estereotipos. Su argumento es conocido. En una celda se encuentran encerrados un militante guerrillero de izquierda y un homosexual condenado por corrupción de menores. La crítica ha insistido en el sistema de dicotomías que la pareja organiza: ambos, en un comienzo, encarnan maniqueamente los roles que la tradición falogocéntrica reparte entre los géneros; su relación se estructura en pares de oposiciones tales como pensamiento/imaginación, racionalidad/ afectividad, rebeldía/resignación, fuerza/debilidad. La narración de las películas que Molina, el homosexual, le cuenta a Valentín, el guerrillero, atraviesa la novela y, mediándola, se cuela el debate acerca de la interpretación de esas películas y acerca de la sexualidad. Luego, los estereotipos comienzan a resquebrajarse, la preocupación por el sentido cede lugar a la fascinación por el relato y el discurso sobre la sexualidad acaba transformándose en silencio ante la consumación del encuentro amoroso.

La celda en la que trascurre la novela constituye una heterotopía, tal como definió Foucault (1997) a esos lugares extraños en los que se ven suspendidas las coerciones del mundo exterior. Aunque disidentes cada uno a su manera, Molina y Valentín no son extraños a la cultura y cargan consigo el peso que esta les ha impuesto: encarnan voluntades reactivas que asumen fuertes mandatos identitarios y prejuicios. Sin embargo, las lógicas diferenciales que el espacio de la celda impone los llevan a establecer un modo de relacionarse alternativo al que podrían haber tenido fuera de ella. La proximidad los pone en estado de apertura al otro y el peso de la cultura va desvaneciéndose. Ese lugar de encierro y malestar se convierte en posibilidad de desujeción y se resuelven microscópicamente los conflictos y las desigualdades de poder del exterior. La celda aparece como campo de pruebas, como tubo de ensayos para la sociedad futurible. Puig afirmaba, en los años posteriores a la publicación de El beso de la mujer araña, que su trabajo seguía una "línea de investigación en el error argentino [...] Error político, error sexual” (Corbatta, 2009, p. 238). La escritura conjetural de la ficción utópica funcionaría de esta manera como un modo de conocimiento y se acercaría a las regiones del ensayo. ${ }^{2}$

La novelística de Puig está atravesada por una insistencia: ficcionalizar la lectura. Los personajes de Puig, al menos en las primeras novelas, son fervientes lectores de los textos de la cultura de masas. Toto, ese niño que, en La traición de Rita Hayworth, se pasa las horas de la siesta en las que la ley paterna impone el silencio recordando las películas que vio junto a su madre, es el lector prototípico de Puig. Relata las películas y en el discurrir de su voz ensimismada su propia vida se cuela y se mezcla con el mundo de las maravillas de Hollywood: de repente su tío, o su maestra, o él mismo, son un personaje más y la trama, como un espejo distorsionado de feria, habla de sí. Sus miedos, sus frustraciones, sus deseos aparecen representados en ese discurso inagotable. Toto lee el texto de las películas desde la vida y, así, el texto se ve transformado en algo distinto a lo que era: es una lectura irreverente e irrespetuosa. A su vez, su propia vida es interpretada a partir de las palabras y las herramientas que la ficción le otorga. Lee el texto desde la vida y la vida desde el texto: esta es la condición paradójica que abre una lectura que estalla los límites entre arte y vida.

Se puede recorrer las novelas de Puig a partir de las variaciones que se van dando en el modo en que ficcionalizan la lectura: desde la saturación de las novelas de Coronel Vallejos hasta el abandono de la lectura en esas novelas casi "despobladas de cultura" (Pauls, 2009, p. 378) que cierran la obra de Puig. Los personajes de Puig leen libros pero también otros textos: películas, tangos, boleros, radioteatros, relatos en la voz de otro.

El de ficcionalización de la lectura -expresión acuñada por Susana Zanetti (2010) - es un operador crítico que señala todo momento o pasaje de un texto ficcional en el que la lectura aparece, de alguna manera, representada, tematizada, rememorada, referida o aludida. Estos pasajes suponen un espacio de 
condensación que permite atravesar las dimensiones de sentido y formales que constituyen un texto; la ficcionalización de la lectura "parece fuera de la novela, pero en buena medida suele vertebrarla, atenta a contribuir a la construcción de sus significaciones” (Zanetti, 2010, p. 11). El concepto es más amplio que el más comúnmente usado de escena de lectura, que refiere a la representación del acto de leer en sí. Hay ficcionalización de la lectura cuando un personaje narra a otro algo que leyó, o cuando recuerda una lectura que hizo previamente aunque ese acto nunca se haya mostrado en la trama del texto, también cuando simplemente se nombra lo leído o se lo cita o cuando se habla acerca de la lectura sin mostrar "el acto mismo de leer" (Molloy, 2001, p. 28). Ninguno de estos casos se puede considerar escena de lectura, que es solo un modo de la ficcionalización de la lectura.

El espacio concreto de la celda, en El beso de la mujer araña, se superpone al espacio imaginario de las ficciones que se narran en ella y las lecturas de cada personaje entran en conflicto. Molina lee, al narrarlas, las películas que vio: rememora el encuentro con el texto y actualiza la lectura en un acto creativo, que es la puesta en narración. Valentín, en cambio, lee en sentido estricto (las lecturas de Valentín constituyen escenas de lectura propiamente dichas). Mientras que Molina es un lector que halla en la lectura un modo de darse un ser en el lenguaje y vive la experiencia de la lectura como un proceso de afectación; Valentín personifica a un lector exegético que lee solo para interpretar intelectualmente los textos y no se deja afectar por el acto.

En cada una de las películas que cuenta Molina se narra la problemática relación amorosa entre una mujer y un hombre ${ }^{3}$ asediados por las condiciones desfavorables que les han tocado en suerte; el final es siempre trágico o amargo. No es incorrecta la comparación repetida por la crítica de Molina con Sherezade ${ }^{4}$, con la salvedad de que aquí la palabra no salva solo al narrador sino, al menos momentáneamente, a ambos: la narración (la lectura) es el refugio bajo el cual hallan un modo de subsistir. Molina conjura con el manto de su voz los riesgos a los que el estado de precariedad en el que se encuentran los expone. No se trata, sin embargo, de un escapismo o una distracción; la narración regresa sobre lo real para nombrarlo. Cada película es una puesta en abismo del modo en que Molina ve la situación en la que se encuentran: impedidos para amarse por las constricciones que la sociedad ha cargado sobre ellos y signados por una realidad desfavorable en la que la vida de ambos depende del arbitrio del aparato represivo. La fatalidad, la imposibilidad y la opresión son la atmósfera de todas las películas;

cada sinopsis cinematográfica que narra Molina es una elipsis de lo que está pasando dentro de ellos y entre ellos; el cine cubre el vacío de eso que no se menciona y va haciendo brotar un fondo de represiones, traumas y prejuicios -la verdad humana de los personajes- que el diálogo directo no habría tal vez logrado (Oviedo, 1977, p. 615).

Molina recrea las películas que vio en un gesto que mezcla indefinidamente lectura y vida, de modo tal que le permitan nombrarse a sí mismo y a su situación en el espacio que el devenir de la voz va construyendo."¿Con quién te identificás?, ¿con Irena o la arquitecta? / -Con Irena, qué te creés. Es la protagonista, pedazo de pavo. Yo siempre con la heroína" (Puig, 2002, p. 21). Molina se proyecta en esos relatos y los construye como una representación solapada de sí. Sus narraciones son siempre juegos especulares en los que halla la posibilidad de verse representado bajo la figura-siempre femenina- del personaje principal.

En Cat people, la primera película que Molina narra, Irena, la protagonista, teme ser la mujer pantera, el monstruo enigmático de una leyenda que circula por su tierra natal y que asegura que, cuando bese a un hombre, se transformará en pantera y lo devorará. "A ella se le ve que algo raro tiene, que no es una mujer como todas" (Puig, 2002, p. 7). Es el incipit de la novela, que es a la vez el comienzo del relato de la película. La rareza es el rasgo que une a todas las mujeres de las películas de Molina. Todas ellas ocultan algo: la mujer que oculta su condición animal, la doble agente de espionaje, la sirvienta cuyo rostro despreciable encubre la belleza, la mujer zombi, la cantante que se prostituye a escondidas de su amado. "Los films se parecen entre sí porque 
tratan un tema común: el de la identidad oculta o doble" (Oviedo, 1977, p. 616). El monstruo humano es, según Foucault, aquel individuo que transgrede las leyes en un sentido jurídico-biológico. "La figura de un ser mitad hombre mitad bestia (...), las individualidades dobles (...), los hermafroditas (...) representan bien históricamente las figuras arquetípicas de esa doble infracción (...). El monstruo humano combina a la vez lo imposible y lo prohibido" (Foucault, 1996, p. 61). Todas las mujeres de las películas comparten la cualidad de lo monstruoso, presentan esta naturaleza doble que las condena a una existencia trágica, a la vez que las hace irresistibles en su misterio. Es la imagen que Molina construye de sí. El monstruo aterra pero también puede fascinar, y el halo fantasmagórico que el relato de las películas va creando cubre la atmósfera de la celda y permite a Molina transfigurarse en esas mujeres-monstruo. Como la mujer pantera, él también tiene miedo "de no ser una buena esposa" (Puig, 2002, p. 18) para Valentín pero, de todos modos, "lo único que quiere es poder despertarse cada día para volver a verlo" (p. 15).

En la tercera película, que Molina narra para sí mismo, una sirvienta que se destaca por su fealdad trabaja para un soldado que la guerra ha marcado con una cicatriz horrenda y que, refugiado en su casa, se niega a ver a nadie y pasa sus días dibujando. En cierto momento, la sirvienta ve uno de los dibujos y le dice una frase que hace que el soldado comience a verla de un modo nuevo: a partir de allí todo se transforma y ella acaba siendo su compañera. Molina no puede recordar esa frase que constituye el quiebre, el pasaje que hace de la sirvienta fea una mujer de la cual enamorarse:

¿qué pasa que a veces alguien dice algo y conquista para siempre a otra persona?, ¿qué era lo que le decía la sirvientita sobre ese dibujo?, ¿cómo consiguió que él se diera cuenta de que ella era algo más que una sirvienta fea? Cómo me gustaría acordarme de esas palabras, ¿qué será que dijo? (Puig, 2002, p. 92)

Es, precisamente, ese tipo de palabras las que él querría ser capaz de decir a Valentín, para que "el elemento de repulsión física [se invierta] en uno de atracción espiritual” (Oviedo, 1977, p. 617) y logre mirarlo como una compañera. La frustración de la memoria es la frustración de su deseo.

Mechándose en la narración de las películas una muletilla insiste. "Te voy a explicar”, dice Valentín y da su análisis del relato. El resultado es la detención: Molina, cada vez, se ofende y deja de contar: “¿Por qué cortarme la ilusión, a mí, y a vos también?, ¿qué hazaña es esa?” (Puig, 22, p. 16). Para Valentín, la lectura es una ocasión para la interpretación (Littau, 28), para aplicar sus saberes y desplegar una labor de exégesis. La explicación de Valentín de Cat People halla en el psicoanálisis la clave interpretativa:

Está bien la película (...) ¿Pero sabés qué me gusta?, que es como una alegoría, muy clara además, del miedo de la mujer a entregarse al hombre, porque al entregarse al sexo se vuelve un poco animal, ¿te das cuenta? (Puig, 2002, p. 30)

Molina, escéptico de los poderes de esa lectura, lo deja hablar, condescendiente. "Seguí, voz de la sabiduría" (p. 31). Y Valentín continúa explicando: "Ahí está el problema, porque él [el psicólogo al que ella teme visitar] la excita, y por eso se resiste a entregarse al tratamiento" (p. 31).

La lectura hermenéutica aunque en un primer momento precisa del texto para hallar las claves de su interpretación, una vez que lo logra puede descartarlo (Valentín ni siquiera ha visto la película ni ha finalizado de escuchar el relato) pues sabe que nada traicionará al orden descubierto de los sentidos que lo conforman. "La lectura hermenéutica supone que el lector lee en espejo, o al menos que para leer tiene que leer en espejo, rechaza la diferencia, y al rechazar la diferencia en lugar de leer el texto no hace más que imaginarizarlo" (Ritvo, 2017, p. 27). Cada momento de la película sirve a Valentín para hallar una confirmación a sus ideas porque su modo de lectura, al partir de la seguridad de lo que debe hallar, no acaba hallando otra cosa que a sí mismo. Valentín sufre de lo que Nicolás Rosa llamó la "pandemia hermenéutica": no hace otra que leer e interpretar al mundo convertido en signo, es una "registradora sígnica 
y una pequeña máquina paranoica de interpretar" (1992, p. 35) y es incapaz de volverse sensible a las potencias de identificación que Molina le ofrece en la narración y a la plasticidad de la materia textual para volverse apropiable.

Nada más ajeno a la hermenéutica que la lectura de los otros personajes de Puig, de personajes como Toto, como la Raba o como Nené de Boquitas pintadas, como Molina: para ellos el texto nunca es un misterio a develar, no esconde ninguna verdad o sentido que debiera descubrirse. La hermenéutica, parece insinuarse, es la negación de la lectura: lo que se juega en la lectura es la vida y no el sentido. La lectura, para estos personajes, es una experiencia vital.

En ese espacio de disponibilidad para hallarse a sí mismo que Molina va escribiendo con su voz, no solo hay lugar para su autorrepresentación desfigurada en lo monstruoso irresistible, sino que hay lugar también -y en esto consiste el poder seductor de su narración- para Valentín. La novela se estructura a partir de este proceso de seducción como un diálogo agónico, una lucha de fuerzas en oposición, casi un diálogo socrático de voces en discusión: la del mentor, Molina, y la del alumno, Valentín. Mientras la voz del alumno se empeña en mantenerse en la comodidad que sus ideas le brindan al permitirle una explicación coherente del mundo y un modo de modificarlo; la voz del mentor intenta rasgar en la grieta que hará que todo el edificio conceptual tambalee. Molina busca mostrar la falla en la univocidad totalizante de los saberes de Valentín porque sabe que aquello que se yergue con la certeza absoluta de sí es ciego a lo que deja afuera. Molina hace vacilar el orden en el que se sostiene no solo la lucha sino toda la existencia de Valentín. No para destruirlo pues, desde su intuitivo modo de concebir el mundo, es sensible a las injusticias contra las que Valentín combate, sino para ponerlo en riesgo, en estado de autoinspección y alarma, para advertirlo de aquello que su discurso niega y excluye al afirmarse. (Esto ya ha sido dicho: en un sentido estrictamente político, El beso de la mujer araña es un manifiesto sobre la necesidad de incorporar la lucha por la liberación sexual a la lucha por la emancipación política, un llamado de atención hacia una concepción homofóbica arraigada en la izquierda de la época). ${ }^{5}$

El convencimiento del otro y la enseñanza no se dan, como en los textos platónicos, a través de la argumentación -aunque también esté presente- sino a través de un lento proceso de seducción. Si Valentín aprende la lección de Molina, es decir, si eventualmente deja atrás las categorías con las que está acostumbrado a analizar los textos y que le impiden un acceso auténtico a la experiencia, logrará reconocerse a sí mismo siendo otro en la lectura. Si es capaz de leer como Molina, podrá verse en el lugar del hombre capaz de salvar a la mujer-monstruo.

La segunda película cuenta la historia de Leni Lamaison, una cantante francesa en los años de la ocupación alemana que se enamora de un oficial nazi. El relato de la película, que constituye -como el de las demás- una ficcionalización de la lectura, está lleno, a su vez, de ficcionalizaciones de la lectura en su interior. Citamos una de ellas por su brevedad y su claridad. Leni y el oficial escuchan música -no se dice pero parece ser Wagner-y ella pregunta por el significado de esa melodía.

Él dice que es su favorita, esas especies de oleadas de violines son las aguas de un río alemán por donde navega un hombredios, que no es más que un hombre pero que su amor a la patria le quita todo miedo [...] La música se vuelve tan emocionante que a él se le llenan los ojos de lágrimas. Y eso es lo más lindo de la escena, porque ella al verlo conmovido, se da cuenta que él tiene los sentimientos de un hombre, aunque parezca invencible como un dios (Puig, 2002, p. 50).

El oficial, al hablar del hombre-dios, habla de sí mismo y crea una imagen de sí para Leni. A su vez, la escena le permite a Molina representar su situación frente a Valentín. En la figura del hombre trascendido por un mandato superior que lo eleva pero que, a la vez, tiene también su costado humano, frágil, Molina le ofrece a Valentín una figura con la cual identificarse y le demuestra que, tal como Leni comprende al oficial, él es capaz de comprenderlo. Esa historia heroica de amor y de lucha, para Molina, es análoga a la historia que ellos dos 
podrían vivir. No es que no sea capaz de ver las diferencias ideológicas opuestas hasta el extremo entre ambos escenarios sino que, en su modo de lectura, lo que importa es el elemento común que permita mezclar la vida con la ficción y que otorgue así una nueva iluminación para observarlas. Valentín, sin embargo, no puede no leer la película como un panfleto nazi y la distancia ideológica que lo separa del personaje del oficial no le permite identificarse. Es una "inmundicia nazi” (Puig, 2002, p. 51), sentencia, y desata el llanto de Molina.

La inmundicia serás vos y no la película (...) Me ofendés porque te... te creés que no... no me doy cuenta que es de propaganda na... nazi, pero si a mí me gusta es porque está bien hecha, aparte de eso es una obra de arte, vos no sabés po... porque no la viste (Puig, 2002, p. 51)

Todo lo que se juegue por fuera de la correlación alegórica queda relegado a la invisibilidad para Valentín. Ritvo afirma que la exégesis alegórica consiste en establecer relaciones de equivalencia entre dos conjuntos y tiene como fin "censurar la dimensión in-quietante del relato" (1992, p. 18) al asegurar un sentido único y originario cifrado en él. Esa es la frustración de Molina, ya que es justo allí, por fuera del sentido obvio del texto, donde, para él, todo sucede. El "no sabés porque no la viste" muestra la brecha que separa a ambos modos de lectura: mientras que Valentín cree que leer consiste en hallar el marco ideológico del relato para realizar desde allí su crítica y que, luego, es posible explicar esa lectura al otro, Molina sabe que, por más que él intente educarlo en su estética en la que arte y vida se diluyen, la lectura es una experiencia que las palabras no pueden nombrar. No hay manera de que Molina obligue a Valentín a leer como él desea que lea. La narración seductora es un convite, un ofrecimiento. Solo tendrá éxito si el otro da el salto que le permita poner en palabras algo que permanecía con anterioridad en él: el acto de leer como catalizador de aquello que permanece reprimido.

La novela reactualiza una preocupación ya presente en Weber, Benjamin o Heidegger: la pérdida de la experiencia auténtica ante el avance de la racionalización del mundo. El concepto de autenticidad, dice Ricardo Forster en su libro sobre Benjamin, "supone que frente a la intelectualización del mundo (...) el hombre está impedido de descubrirse como mundo y como vivencia. Y que hay que dejar que lo verdadero, lo auténtico, la vivencia se exprese contra el dominio de la intelectualización” (2012, pp. 136-137). En la conversación en la intimidad de la celda pugnan la experiencia auténtica, representada en Molina, y el mundo intelectualizado, representado por Valentín. Acabará ganando la primera. Las primeras señales de una transformación en el modo de lectura de Valentín se dan ya en la primera película, cuando comienza a nombrar a la arquitecta, personaje secundario, como su novia y cuando la relaciona con su compañera, que está afuera. Pero será en el mundo onírico, en los sueños de la enfermedad en que la comida intoxicada lo sumerge, que su lectura comience a dejar atrás las categorías ideológicas desde las que opera. Molina le ha contado una película acerca de un hijo de familia acomodada que tiene ideas de izquierda y desea hacerse revolucionario. Se la cuenta, aunque a él no le gusta, para complacerlo y porque cree que el personaje se le parece. Valentín niega esa similitud que, sin embargo, es evidente. Cuando cae dormido, su mente agitada continúa un relato imaginario a partir de los pocos datos de la película que Molina le dio. Algo lo ha conmovido y le hace insistir en el texto de esa película que le ha llegado escamoteado, como si explorando sus posibilidades narrativas se explorara a sí mismo y pudiera poner en palabras la culpa que siente por provenir, al igual que el personaje, de una familia adinerada y no de las capas humildes de la sociedad.

Fuera del permisivo mundo del sueño, es un bolero el texto con el que Valentín comienza a dar el giro en su modo de lectura. Ha recibido una carta, escrita en clave, de su compañera, en la que le cuenta que ha muerto uno de sus compañeros y que ella ha comenzado a tener relaciones con otro que él no conoce. Molina no puede evitar la asociación del bolero con la carta que ha llegado -es, casi, un acto reflejo: su modo de lectura es un modo de habitar el mundo- y canta un bolero de Mario Clavel, "Mi carta": "Querido, vuelvo otra vez a conversar contigo... La noche, trae un silencio que me invita a hablarte... Y pienso, si tú también estarás recordando, cariño... los sueños tristes de este amor extraño..." (Puig, 2002, p. 118). Luego se disculpa 
a Valentín por la inconveniencia. Sin embargo, Valentín acaba haciendo la conexión. Descubre que puede haber un pasaje entre el arte y la vida que no sea el de la crítica:

-Sabés una cosa... yo me reía de tu bolero, y la carta que recibí por ahí dice lo mismo que el bolero.

$-¿$ Te parece?

-Sí, me parece que no tengo derecho a reírme del bolero.

-A lo mejor vos te reíste porque te tocaba muy de cerca, y te reías... por no llorar. Como dice otro bolero, o un tango

(Puig, 2002, p. 120) 6 .

Valentín insiste en su nuevo descubrimiento: “y como dice tu bolero, 'porque la vida no nos unirá nunca', al pobre muchacho [que murió] ya nunca más le voy a poder escribir una carta, ni decirle una palabra” (Puig, 2002, p. 125). Ha completado su iniciación. El modo de lectura que enseña Molina, señala la novela, no es más que el modo reprimido en que cualquiera, si rompe sus ataduras conceptuales, se puede entregar al encuentro con el texto.

Oviedo, cuyo temprano y lúcido trabajo hemos citado ya en reiteradas oportunidades, señala, por último, que la sexta película, el melodrama mexicano de los capítulos finales de la novela, "despierta en Valentín ciertas reflexiones que más parecerían de Molina" (1977, p. 619):

Aunque ella se haya quedado sin nada, está contenta de haber tenido por lo menos una relación verdadera en la vida, aunque ya se haya terminado (...). En la vida del hombre, que puede ser corta y puede ser larga, todo es provisorio. Nada es para siempre" (Puig, 2002, p. 236)

Ambos están, por fin, igualados en su modo de lectura y ya no los media ese contrato de educación nunca enunciado ni admitido.

6

El beso de la mujer araña despliega toda una didáctica de la lectura. Se cumple aquello que Susana Zanneti (2010) reconoce en las ficcionalizaciones de la lectura en la literatura del xix: una dimensión performativa, la intención de actuar sobre los lectores concretos prescribiendo modos de leer y exponiendo las pautas para entender el relato en el que aparecen (también Ricardo Piglia (2014), en un sentido similar, piensa las representaciones imaginarias del acto de leer como lecciones de lectura). En "El narrador" Benjamin recuerda cómo la figura del narrador y la del sabio coinciden: el narrador es alguien que, desde su experiencia, "tiene consejos para el que escucha" (2008). Molina no da consejos a Valentín -su relato no es ejemplificador, aleccionador, ni útil- pero no deja, sin embargo, de ejercer una educación. Esta educación en la lectura que la novela narra es, a la vez, una educación en lo sexual. Puig construye a ambas como alegorías recíprocas. Sexualidad y lectura son significantes intercambiables porque el gesto que la novela traza es idéntico en ambas dimensiones: tanto a nivel cultural como a nivel sexual pone en cuestión los órdenes establecidos y las prácticas hegemónicas (Amícola, 1995). Puig escribe a partir de un impulso utópico (Kurlat Ares, 2017): no es el escenario de la utopía el que aparece representado pero la utopía está siempre presente como horizonte. ${ }^{7}$ Se trata de la utopía del fin de los autoritarismos, de lo autoritario en la microscopía del poder en las relaciones íntimas y en los regímenes de valoración que configuran los discursos del saber (los saberes sobre la cultura, los saberes sobre las identidades, los saberes sobre el sexo y el texto). ${ }^{8}$

En la escena final de la novela nos hallamos con un Valentín devastado por la tortura, quizá a punto de morir, flotando en el sueño en el que la morfina lo sumió. Leemos el fluir de su conciencia y hallamos que, a pesar de la tragedia del periplo de esos cuerpos expuestos al designio del poder (Molina ha muerto en un confuso episodio a manos de los compañeros de Valentín; él yace encerrado todavía en su celda), la historia de su proceso de enseñanza ha tenido un final feliz. A partir de la materia de las películas que Molina le contó, Valentín discursea locamente y en su discurso Molina aparece en la selva (evocación de La vuelta la mujer 
zombi, una de las películas narrada) como una mujer vestida de plateado y con una máscara por la que corre una lágrima como un diamante (como en Destino, la película nazi).

Y yo le pregunto por qué es que llora [dice Valentín en el delirio de la morfina] y en un primer plano que ocupa toda la pantalla al final de la película ella me contesta que es eso lo que no se sabe, porque es un final enigmático, y yo le contesto que está bien así, que es lo mejor de la película porque significa que... y ahí ella no me dejó seguir, me dijo que yo quería encontrarle explicación a todo (Puig, 2002, p. 257).

A la incontinencia interpretativa del análisis exegético ya le ha llegado el momento de callar. Valentín comprende que no debe hallarle explicación a todo, que la explicación cierra la multiplicidad a lo único y que, en cambio, lo que Molina le ha ofrecido es la siempre múltiple experiencia incalculable de lo posible: "la mujer-araña me señaló con el dedo un camino en la selva, y ahora no sé por dónde empezar a comer tantas cosas que me encontré" (p. 257).

La escritura de Puig apuesta a lo oblicuo, a lo indefinido, a lo azaroso en oposición a la univocidad de las identidades monolíticas que se reafirman en su mismidad irrenunciable: al hombre macho, a la mujer sumisa, a la idea del lector enajenado que se entretiene con basura industrial, a la del lector culto que analiza la construcción ideológica de los textos, en definitiva, a cada sitio en el que la cultura demanda la repetición estereotipada de los roles, Puig opone la sorpresa del corrimiento -sutil o grandilocuente- de los lugares y los modos de ocurrencia. La doble política - política sexual y política de la lectura- es, a fin de cuentas, solo una, la misma que estructura toda la literatura de Puig: la impugnación de aquello que al estar estatuido genera prácticas y configuraciones opresivas de los modos de ser y de relacionarse. Es una política de la disolución y la mezcla: llevarlo todo a la insustancialidad y la indeterminación, abrirlo a la infinidad de lo posible.

\section{7}

El aprendizaje de Valentín es, en conclusión, múltiple. Del dogmatismo hermenéutico nutrido de las vulgatas del marxismo y el psicoanálisis a la lectura como acto identificatorio y ocasión para la construcción de un relato de sí; del etnocentrismo intelectual (Bourdieu, Chamboredon y Passeron, 2002) a la apertura a modos diferenciales de experienciar la cultura; del heteronormativismo a la práctica de una sexualidad disidente. Todos estos pasajes constituyen la anécdota principal de la novela. Pero hay otro aprendizaje detrás de esto. Un aprendizaje subrepticio, que no acaba de nombrarse nunca pero que, hacia el final, estalla con la violencia de una epifanía. Se trata del aprendizaje ético de Molina. Mientras que la novela expone abiertamente su didactismo en lo que respecta a la lectura y la sexualidad, otra enseñanza, cuyo capítulo final es la muerte martirial de un Molina entregado a la causa de la revolución, se va dando disimuladamente. Es una enseñanza política en el sentido más estricto del término. En el final de la novela se revela su carácter jánico. Allí cuando el despliegue del diálogo socrático anticipaba el pasaje del iniciado de la ignorancia al saber, la novela otorga, además, lo inesperado, y desestabiliza la construcción que venía realizando: descubrimos, sorprendidos, que el maestro se ha transformado también. El esquema didáctico se resquebraja por la fuerza de este pasaje. Aunque la educación haya sido unilateral -las pocas incitaciones de Valentín para despertar el interés político de Molina han caído todas en saco roto-, el aprendizaje ha sido doble y ni un personaje ni el otro son, al final, lo que eran en un principio.

Molina, luego de ser liberado, ha decidido reunirse con los compañeros de Valentín para entregarles alguna información. La primera reunión no ha resultado porque la policía no deja de seguirle los pasos y los militantes lo notan y no se presentan. La segunda reunión parece ir por el mismo camino pero esta vez la policía tiene decidido apresar a Molina e interrogarlo. Cuando están a punto de hacerlo, los compañeros de Valentín pasan en un auto y dan una ráfaga de disparos que hiere a un oficial y mata a Molina. El hecho de que Molina haya sacado su dinero del banco antes de este suceso y se lo haya entregado a su madre da a entender que él esperaba un final de este tipo. Antes que ver en este acto último el gesto bovarista de pretender parecerse 
a las heroínas sacrificiales de sus películas, lo que se manifiesta es la toma de conciencia política a partir de la experiencia afectiva. Si Valentín ha experimentado, seducido por la voz narradora de Molina, la lectura como acto transformador en el encuentro íntimo con el texto, Molina, por su parte, ha visto, una vez corridos por la intensidad amorosa los velos de la frivolidad y el desinterés, la nobleza de un cuerpo y una conciencia comprometidos con una causa, y se ha transformado él también.

Podemos leer el sacrifico de Molina en los términos del sacrificio de las heroínas de Hollywood, pero también en los términos de un planteo político. La relación entre amor imposible y novela política permite situar esta novela junto a Amalia: el amor imposible implica una decisión que supone enfrentar un riesgo en el plano político. (Piglia, 2016, p. 156)

De alguna manera, Puig entendió que la lección que su literatura era capaz de dar -que la experiencia estética es transformadora- podría servir también para fines políticos. Descubrió no solo lo que hay de político en la novela -esto lo sabía ya desde un primer momento cuando decidió narrar el habla anónima de los sujetos triviales de un pueblo perdido de provincia- sino también lo que hay de novelesco en la política. Es el descubrimiento de una épica del siglo xx. El mismo descubrimiento que realizara Walsh: mientras Puig publicaba El beso de la mujer araña, Walsh escribía su "Carta a mis amigos", donde el relato de la muerte de su hija frente a un pelotón del ejército se conjugaba con el relato íntimo del vínculo que los unía: minuciosa liturgia de cinco minutos cada quince días en la que los dos se daban la anticipada despedida porque quienes habían consagrado la vida a la lucha no precisaban de los dones oraculares para conocer el final que la época les reservaba. La literatura, es Puig y en Walsh, modo de descubrir (de hallar pero también de revelar) lo que puede una vida militante, no tanto por su hacer sino por su estar-ahi como presencia denunciataria de un malestar, como testimonio de lo que es capaz un sujeto entregado a una causa: su poder de fascinación -tan potente como el de un film-, su punzante incomodidad, su potencia para desestabilizar los órdenes estatuidos si se la percibe (si se la lee) desde una mirada en estado de apertura infinita, tal como se debe leer cualquier texto para que algo auténtico suceda.

\section{REFERENCIAS}

Amícola, J. (1995). “Gender” y “genre” en Manuel Puig. Lateinamerika-Studien, (36), 155-163.

Amícola, J. (2007). Puig's Poetics of Fusion. En D. Balderston y F. Masiello (eds.), Approaches to Teaching Puig's Kiss of the Spider Woman (83-90). New York: The Modern Language Association of America.

Balderston, D. y Quiroga, J. (2005). Sexualidades en disputa. Homosexualidades, literatura y medios de comunicación en América Latina. Buenos Aires, Argentina: Libros del Rojas.

Benjamin, W. (2008). El narrador. Ensayos estéticos y literarios (Vol. 2). Madrid, España: Abada.

Bourdieu, P., Chamboredon, J.; Passeron, J. (2002). El oficio del sociólogo. Presupuestos epistemológicos. Buenos Aires, Argentina: Siglo Veintiuno.

Corbatta, J. (2009). Manuel Puig: mito personal, historia y ficción. Buenos Aires, Argentina: Corregidor.

Forster, R. (2012). Benjamin: una introducción. Buenos Aires, Argentina: Quadrata.

Foucault, M. (1997). Los espacios otros. Astrágalo, (7), 83-91.

Foucault, M. (1996). La vida de los hombres infames. Buenos Aires, Argentina: Altamira.

Garrido Domínguez, A. (2000). M. Puig: Cine y literatura en El beso de la mujer araña. Anales de literatura hispanoamericana, 29, 75-102. Recuperado de http://revistas.ucm.es/index.php/ALHI/article/view/ALHI00 $00110075 \mathrm{~A}$

Goldchluk, G. (2019). Literatura y política: Actas de una convivencia insoportable. En de F. Cesare y M. Giovannini (eds.), Lenguajes de la política: más allá de las palabras (pp. 225-234). Nápoles, Italia: Unior Press; Università degli Studi di Napoli "L'Orientale".

Kurlat Ares, S. (2017). Entre la utopía y la distopía: política e ideología en el discurso crítico de la ciencia ficción. Revista Iberoamericana, LXXXIII(259-260), 401-417. https://doi.org/10.5195/reviberoamer.2017.7507 
Littau, K. (2008). Teorias de la lectura: libros, cuerpos y bibliomania. Buenos Aires, Argentina: Manantial.

Maristany, J. (2006). Figuraciones literarias del homoerotismo en la ficción de los 60/70. Hologramática literaria, 2(3), 5-29. Recuperado de http://www.cienciared.com.ar/ra/doc.php?n=464

Molloy, S. (2001). Acto de presencia. La escritura autobiográfica en Hispanoamérica. México D. F., México: Fondo de Cultura Económica.

Muñoz, E. (1986). El discurso utópico de la sexualidad en El beso de la mujer araña, de Manuel Puig. Revista Iberoamericana, LII(135-136), 361-378. Recuperado de https://revista-iberoamericana.pitt.edu/ojs/index.php /Iberoamericana/article/view/4173/4341

Oviedo, J. (1977). La doble exposición de Manuel Puig. Eco, (192), 607-626.

Páez, R. (1995). Manuel Puig. Del pop a la extrañeza. Buenos Aires, Agentina: Almagesto.

Pauls, A. (2009). Manuel Puig: la zona íntima. En S. Iparraguirre (Coord.), La literatura argentina por escritores argentinos (pp. 377-388). Buenos Aires, Argentina: Biblioteca Nacional.

Perlongher, N. (1986). Molina y Valentín: el sexo de la araña. Tiempo argentino/Cultura. Buenos Aires.

Perrin, A. y Zmantar, F. (1981). La telaraña modela organización textual en El beso de la mujer araña de Manuel Puig: elementos para una hifología del texto. Organizaciones textuales (textos hispánicos). Actas del III Simposio del Séminaire d'etudes littéraires de l'Université de Toulouse-Le Mirail. España: Université de Toulouse II-Le Mirail.

Piglia, R. (2014). El último lector. Buenos Aires, Argentina: Debolsillo.

Piglia, R. (2016). Las tres vanguardias. Buenos Aires, Argentina: Eterna Cadencia.

Puig, M. (2002 [1976]). El beso de la mujer araña. Buenos Aires, Argentina: ALLCA XX.

Ritvo, J. (1992). La edad de la lectura. Rosario, Argentina: Beatriz Viterbo.

Ritvo, J. (2017). Primera clase de Teoría de la lectura, año 1985. En R. Bianchi y E. Elizondo (Comps.), No hay teoría de la lectura (pp. 17-32). Rosario, Argentina: Cátedra de Teoría de la lectura, Facultad de Humanidades y Artes, UNR.

Rosa, N. (1992). Artefacto. Rosario, Argentina: Beatriz Viterbo.

Silva Alves, W. (2011). Narrar para resistir: diálogo y seducción como estrategias de resistencia en El beso de la mujer araña, de Manuel Puig. Espéculo, (47). Recuperado de http://webs.ucm.es/info/especulo/numero47/manpuig .html

Waisman, S. (2003). The thousand and one nights in Argentina: translation, narrative and politics in Borges, Puig, and Piglia. Comparative literature studies, 40(4), 351-371. Recuperado de https://www.jstor.org/stable/pdf/40247 403.pdf

Zanetti, S. (2010). La dorada garra de la lectura: lectoras y lectores de novela en América Latina. Rosario, Argentina: Beatriz Viterbo.

\section{Notas}

1 "El ambiente en el que transcurre El beso de la mujer araña es totalmente nuevo para los lectores de Puig: no la vida doméstica de Coronel Vallejos, sino la de una conocida cárcel (la de Villa Devoto) en Buenos Aires: no el chismoso rumor de las familias de provincia, sino el diálogo de los presos; no las décadas del 30 y 40, evocadas románticamente, sino el presente inmediato, marcado por la violencia política y la represión policial de la Argentina real" (Oviedo, 1977, pp. 613-614).

2 Para Puig lo que diferencia al novelista del ensayista es "una actitud". "El novelista tiene [frente al ensayista] la ventaja de poder usar la fantasía y de ser subjetivo, de identificarse con lo que se trata" (Corbatta, 2009, p. 257).

3 La excepción es la cuarta película, que Molina cuenta para complacer a un Valentín enfermo, y "es de esas películas que les gustan a los hombres" (Puig, 2002, p. 101).

4 Ver: Garrido Domínguez (2000), Waisman (2003), Amícola (2007), Piglia (2016).

5 Ver: Perlongher (1986), Balderston y Quiroga (2005), Maristany (2006). 
6 Graciela Goldchluk (2019) realiza una lectura geneticista de este pasaje, a partir de las insistentes tachaduras y reescrituras a través de las que Puig llegó a la frase "no tengo derecho a reírme del bolero", y da cuenta de la importancia estructural que tiene para el desarrollo de la novela y del personaje de Valentín este momento.

7 "Toda narración de Manuel Puig da cuenta de una cadena de utopías que se pueden circunscribir a una, la de escapar al lugar de cada uno en la posición que una serie de coordenadas le asigna." (Páez, 1995, p. 101).

8 Por razones de espacio no podemos desarrollar aquí la política sexual presente en la novela, pero es un aspecto que la crítica ha trabajado con insistencia: Páez (1995), Muñoz (1986), Perrin y Zmantar (1981), Maristany (2006), Amícola (1995 y 2007), Perlongher (1986), Balderston y Quiroga (2005). 